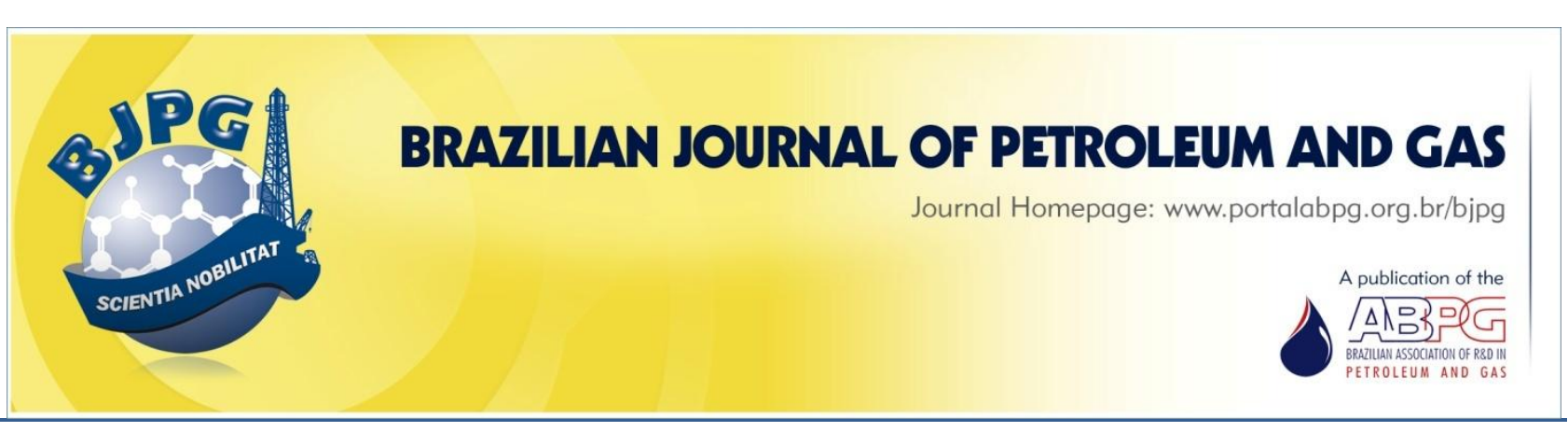

\title{
NUMERICAL SIMULATION OF DRILLING FLUID BEHAVIOR IN DIFFERENT DEPTHS OF AN OIL WELL
}

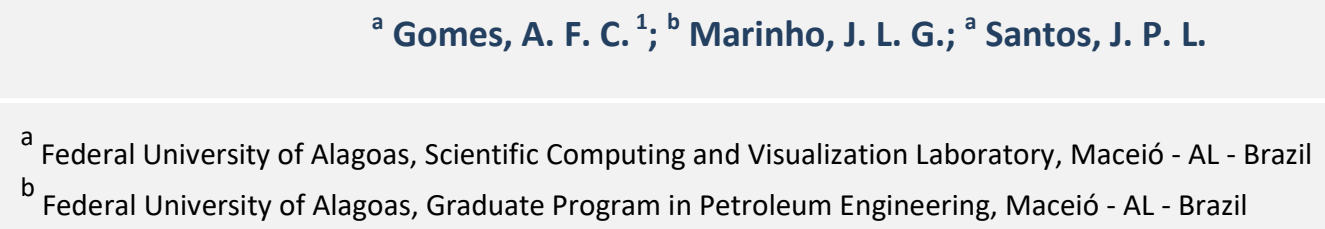

\begin{abstract}
When drilling an oil well, a viscous fluid is injected to aid drilling. This fluid is also responsible for removing the cuttings and maintaining structural stability of well. The rheology of this drilling fluid has a direct influence on the cleaning of the well, on the dynamics of the fluid in pipe and annular areas. Linear mathematical extrapolations for high pressure and high temperature environments can lead to rheology errors up to $75 \%$. In this study, a finite volume model was developed to simulate the flow of a waterbased mud in annular and jetting environments in the drilling environment. Annulars were made by steel pipes and permeable formations. The fluids evaluated were developed empirically with xanthan gum and bentonite clay. The numerical results are consistent with literature and represent characteristics of a Yield Power Law fluid and a Bingham plastic. A comparison was made with water, allowing a correlation between rheological effects and fluid dynamics in annular and high vorticity regions.
\end{abstract}

\section{KEYWORDS}

finite volume; water-based mud; rheology

\footnotetext{
${ }^{1}$ To whom all correspondence should be addressed.

Address: Federal University of Alagoas, Centro de Tecnologia, Av. Lourival Melo Mota - Cidade Universitária, Maceió, AL, Brazil. ZIP Code: 57072.900 | Phone number: +55 2182 3214-1292 | e-mail: andersonfgomes@lccv.ufal.br doi:10.5419/bjpg2019-0026
} 


\section{INTRODUCTION}

Despite the increasing challenges in obtaining oil, it remains an essential raw material with a strong economic impact in our society. As a result, in an attempt to overcome such difficulties, researchers work continuously on developing rapid technological adaptations for drilling into deeper and more extreme wells. Shadravan and Amani (2012) mentioned that several researchers agree that new reservoirs will present growing difficulties in obtaining oil, compelling the industry to seek more precise and reliable techniques to ensure the viability of fields.

During oil well drilling, a viscous fluid, known as drilling fluid, is continuously injected downwards from the surface into the piping (drill string), exiting through the drill bit. This fluid carries, to the surface, solid rock formation debris capable of interfering with drilling. The rheology of a drilling fluid has a direct influence on the dynamics of the fluid in pipes and annulars. This is the equivalent to circulating density and the optimization of the mud circulation system (API 13D, 2009).

The flow of a fluid between the walls of two tubular elements (concentric or eccentric), the annular flow, often is found in industrial situations (Hanks, 1979). In well drilling, this type of flow usually occurs between the drill string (such as inside diameter) and the open well, casing, or drill riser.

Numerical simulations can contribute to predicting future process behaviors. The evolution of such simulators and of the mathematical equations on which they are based are important to finding solutions to the increasing challenges encountered in drilling wells. Computational fluid dynamics (CFD) is a powerful tool for modeling fluid flow from mass, energy, and momentum balances (Chung, 2010).

An aqueous drilling fluid based on bentonite clay and xanthan gum was developed in laboratory. Its rheological properties were measured to feed a numerical finite volume model, with the computational fluid dynamics package Ansys, to study the flow of this non-Newtonian fluid in an annular environment. The model used conditions that simulated a well in a state of drilling at two different depths, one with the presence of an intermediate casing and the other in a well opened to rock formation.

In laminar flow, the fluid layers move like sheets of paper in a large ream. The movement is sheet by sheet, in this case, layer by layer, so that there is no macroscopic mixture (unlike the turbulent flow) with parabolic velocity distribution in steady state inside circular tubes. The maximum velocity is at the center of the flow and minimum velocity is at neighboring of the tube walls, as shown in Figure 1.

According to Machado (2002), all fluids with a variable relationship between shear stress and shear rate, considering isothermal and isobaric conditions and laminar flow, is considered nonNewtonian. Therefore, the viscosity of these fluids is not constant, varying with the magnitude of the shear rate.

Fluids with so-called yield stress limits (such as Bingham plastic fluid or Herschel-Bulkley fluid) require a minimum shear stress to initiate shear flow. Before reaching this flow limit, the fluids

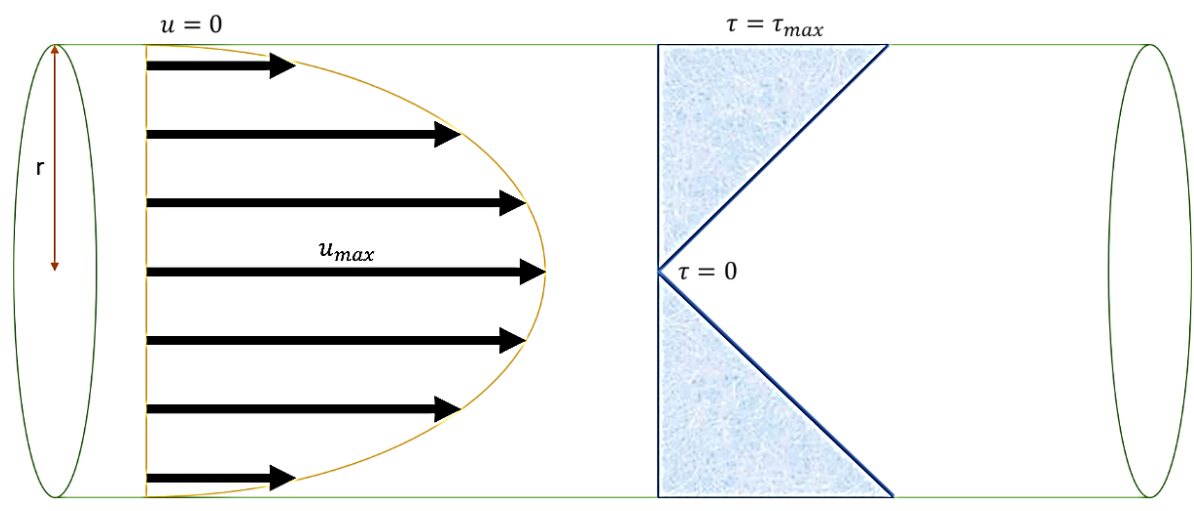

Figure 1. Velocity and stress distribution of a fluid flowing through a pipe in laminar regime. 


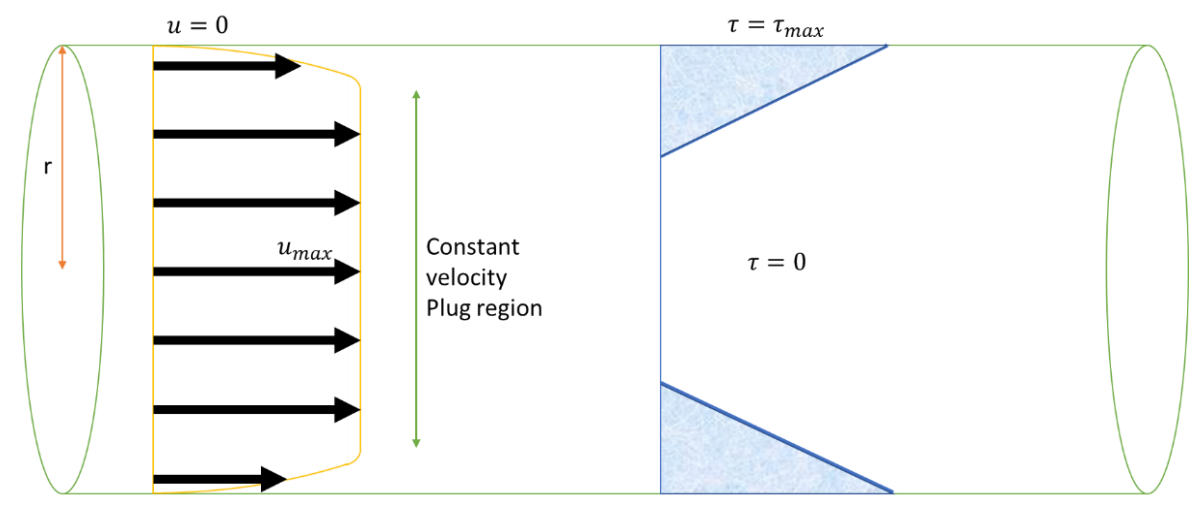

Figure 2. Velocity and stress distribution of a fluid flowing through a pipe under plug flow.

behave as a mediator between fluid and solid flowing in plug form. The flow occurs without relative slippage between the innermost fluid layers, as can be seen in situations involving toothpastes, for example. For this purpose, it is necessary to have a finite and non-null yield stress in the fluid (Machado, 2002). This phenomenon occurs at extremely low speeds or in fluids highly resistant to self-flow, and it refers to that observed in Figure 2.

Bingham's plastic fluid can be mathematically defined by equation (1), where $\tau$ refers to shear stress, $\gamma$ is shear rate, $\mu_{p}$ is plastic viscosity, and $\tau_{0}$ is yield stress limit (since $\tau>\tau_{0}$ ):

$\tau=\tau_{0}+\mu_{p} \cdot \gamma$

In the case of fluids that present power behavior, Ostwald de Waele model enables an exponential relationship between stress and shear rate, where $K$ is called the consistency index and $n$ is the behavior index:

$\tau=K \cdot \gamma^{n}$

Both rheological models involve two-parameter equations (flow limit and plastic viscosity in first case and indexes of consistency and behavior in the power fluid). Oil well drilling fluids usually present flow limit, but also power behavior. With this in mind, neither of the two models recognize and characterize a significant part of the drilling fluids. Therefore, the Herschel-Bulkley model was proposed as a model that encompasses the two parameters (Herschel \& Bulkley, 1926). This model, also called the Yield Power Law (YPL) model, encompasses the behavior index to Bingham's plastic equation in the form:
$\tau=\tau_{0}+K \cdot \gamma^{n}$

The largest drop in pressure in circulation system (50 to $70 \%$ ) occurs in drill jets, where the abrupt reduction and expansion of the transverse area generates intense pressure differentials. This behavior should be observed, therefore, in the fluid dynamic aspect of jetting in drill region.

The development of a fluid dynamic profile in drill region turned out to be of a different complexity than other areas. The numerical instability generated by intense changes in crosssectional areas, as well as shock of fluid at high velocity in normal plane to the flow stimulated the use of a simpler geometry of a drill with three jets without inclination.

Due to a lack of studies on fluid dynamics under extreme conditions. Also, considering that HPHT wells require about $30 \%$ more time for drilling, triple non-productive time and higher frequency of kicks, several researchers have dedicated themselves to studying the feasibility of extrapolations of rheological and fluid dynamic parameters under these conditions (Rassenfoss, 2014).

According to Rassenfoss (2014), when tests were carried out to verify whether hydraulic models could simply be extrapolated to HPHT conditions, mathematical predictions for density had errors of about $50 \%$, while viscous conditions had errors of almost $75 \%$. From real data it was possible to elaborate new equations with good correlations, but consistent only with the extrapolations already made. Nevertheless, the problem of finding solutions to new configurations and extrapolations persisted. 
Lee et al. (2012) studied the rheology of oilbased drilling fluids under extreme HPHT conditions (above 30,000 psi and 500 으 or $260^{\circ} \mathrm{C}$ ) using four different HPHT viscometers. The authors generated a simple mathematical model to measure the rheology of reverse emulsions (oilbased fluids) under extreme conditions. Their tests indicated that several factors can influence rheological measurements, such as the chemistry of the drilling fluid and the configuration of the equipment.

Rheology and hydraulics in the drill region are essential for the cleaning of the well since they allow a higher penetration rate of the drill. Well cleaning refers to the transport and suspension of cuttings by the drilling fluid. Inefficient well cleaning can lead to serious problems such as column entrapment, premature wear, reduction in penetration rate, torque, and difficulties in conducting drilling and liner installation.

Among important variables for optimizing well cleaning (Cameron, 2001) are hydraulic pressures, pressure drops, rheological properties, and efficiency in transporting solids. The so-called sliding speed, a parameter related to the cleaning of the well, reduces significantly with the increase of the mud flow, so that there is an increase of the cuttings transport (Lim \& Chukwu, 1996).
In addition, it is important to understand the phenomenon of drilling at great depths in accordance with what was previously stated. Pressure and temperature conditions influence mud rheology and hydraulic complexity. These conditions can possibly affect the rate of penetration and the ability to drag solids at great depths. The fluid output in the drill region registers important vorticity effects that would negatively influence, for example, the calculation of the pressure drop in the region near the drill.

According to Moslemi and Ahmadi (2014), the cuttings transport rate (one of the most important performance variables of a drilling fluid) is linked directly to jet velocity and depends on the density and rheology of a drilling fluid (Caenn et al., 2011). The global criteria for optimization of drill hydraulics was established by Kendall and Goins Jr. (1960) and has a significant influence on the hydraulics of the drill region.

\section{METHODOLOGY}

The ANSYS computational package 13.0 and its modules were used to process computational fluid dynamics in four macro-stages: physical definition of the problem, pre-processing, solver, and postprocessing, according to the flowchart in Figure 3.

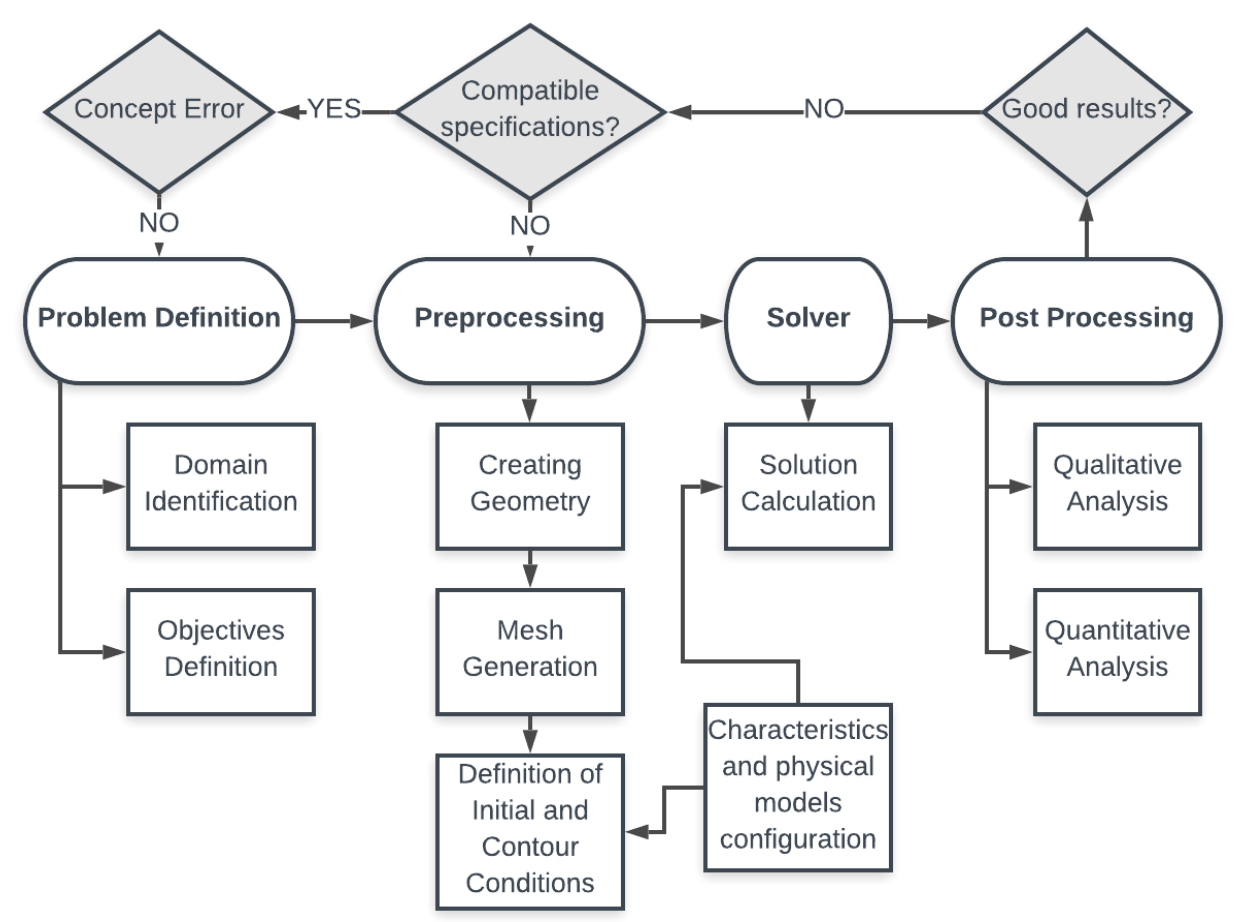

Figure 3. Flowchart of CFD analysis. 


\subsection{Physical definition}

It is considered a rocky region in which a drilling well was generated. The depth of oil wells can reach a few kilometers deep, so modeling the entire geometry is not feasible as it would take an unreasonable time and effort to compute it. Thus, two depths were considered: one for annular flow between the column and the intermediate lining and one in the drill region to visualize turbulent blasting effects at the exit of the column, as shown in Figure 4.

Thus, two experimental fluids were planned for the study: a Bingham plastic fluid (Fluid 1) and a yield power law (Fluid 2). These fluids were prepared in Laboratório de Reservatórios e Poços (LERP) from the Federal University of Alagoas (UFAL), Brazil, with the compositions shown in Table 1 (API Spec 13A, 2006; Caenn et al., 2011; Melo, 2008). Rheological parameters fed the finite volume model.

To obtain these rheological parameters, API 13D (2009) suggests the calculation from the deflections $\left(D_{n}\right)$ obtained for the lowest and highest rotations of the Fann 35A viscometer demonstrated in Equations 4, 5, and 6. It is important to maintain the coherence of the units worked since the equipment provides responses in lbf and $f t^{2}$ while the calculations performed numerically used measurements in International System of units $(\mathrm{Pa})$.

$\tau_{0}=2 \cdot D_{3}-D_{6}$

$n=3.32 \cdot \log _{10}\left(\frac{D_{600}-\tau_{0}}{D_{300}-\tau_{0}}\right)$

$K=\frac{D_{300}-\tau_{0}}{511^{n}}$

Some simplifications were adopted aiming at saving computational resources and complexities not inherent to the proposed work, among other possible contingencies:

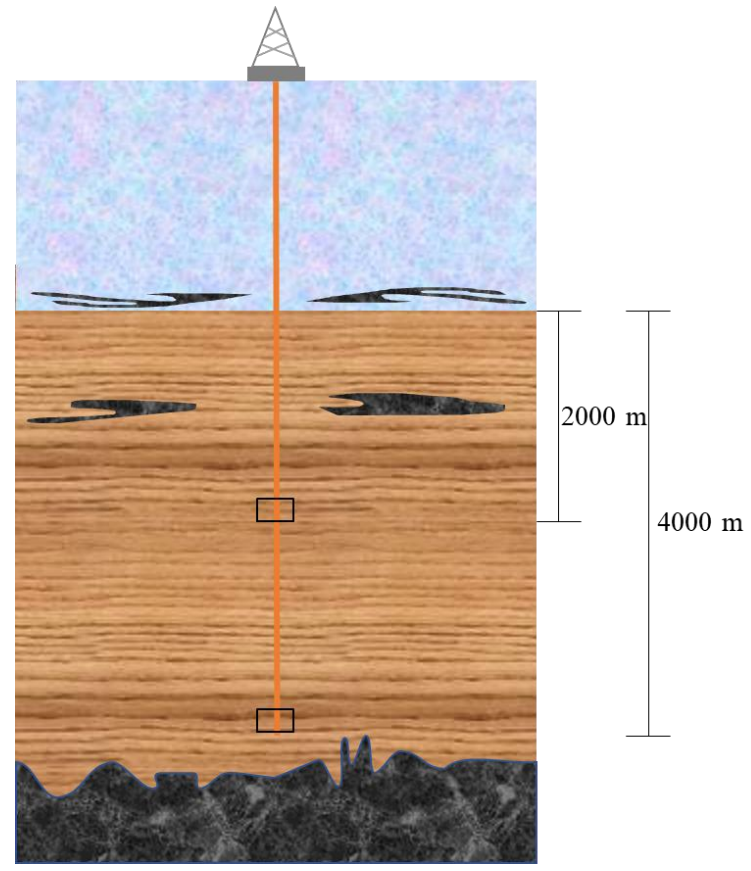

Figure 4. Global scheme with illustration of the drilling area.

i. Constant permoporous properties in rock formation. Directional variations of porosity and permeability would make the model more complex and challenging, and the focus of the work is not on horizontal flow.

ii. Absence of chemical interactions. Chemical reactions would increase the complexity of the model and the work was based only on the physical interaction of the fluid with the adjacent domains.

iii. Heat exchange neglected. The heat transfer equations would considerably increase the demand for computational effort so that the evaluated domains were considered in an isothermal state during the tests, which is a reasonable simplification given the short dimensions considered.

iv. Neglected buoyancy. For dealing with small dimensions, the buoyancy was neglected. Tests performed with the model showed no difference in results, despite causing horizontal anisotropies.

Table 1. Fluids composition in $400 \mathrm{ml}$ of distilled water.

\begin{tabular}{llrrr}
\hline Fluid & Component & Concentration & \multicolumn{1}{c}{ Theoretical Mass } & \multicolumn{1}{c}{ Real Mass } \\
\hline 1 & Bentonite clay & $8 \%$ & $34.7826 \mathrm{~g}$ & $34.7823 \mathrm{~g}$ \\
& Xanthan Gum & $0.8 \%$ & $3.2258 \mathrm{~g}$ & $3.2254 \mathrm{~g}$ \\
2 & Bentonite clay & $4.86 \%$ & $20.4330 \mathrm{~g}$ & $20.4329 \mathrm{~g}$ \\
\hline
\end{tabular}


v. No solid drag. A considerable increase in complexity would occur in the case of solid particles carried by the drilling fluid.

vi. Single-phase flow. No other fluids were considered in region.

\subsection{Geometric model, mesh, and domains}

For two kilometers depth, an intermediate casing ( 20 inches of inside diameter and 1" thick) is considered to form an annular with the drill string (4 inches outside diameter), as shown in Figure 5, thus, forming a 301.6 square inch annular.

While in upper depth only the ascending fluid flow is considered; in the four-kilometer depth, the end of the descending flow is considered. It exits through a simplified drill with three equidistant vertical holes. It presents an ascending turn through the region formed between the column (with now 8" of outer diameter) and the adjacent porous domain with 13.625", 2e-14 $\mathrm{m}^{2}$ of permeability (0.0203 Darcy) and $20 \%$ of porosity (assuming the existence of an obturing cake with low permeability). Both geometries are 250 inches in total length. Figure 6 shows the dimensions in the lower depth.

Both the solid (referring to drill strings and casing) and porous domains (rock formation adjacent to the $4 \mathrm{~km}$ depth) maintained initial refinement (aiming at reducing computational effort). In the case of fluid domains, maximum element sizes were defined as a refinement control

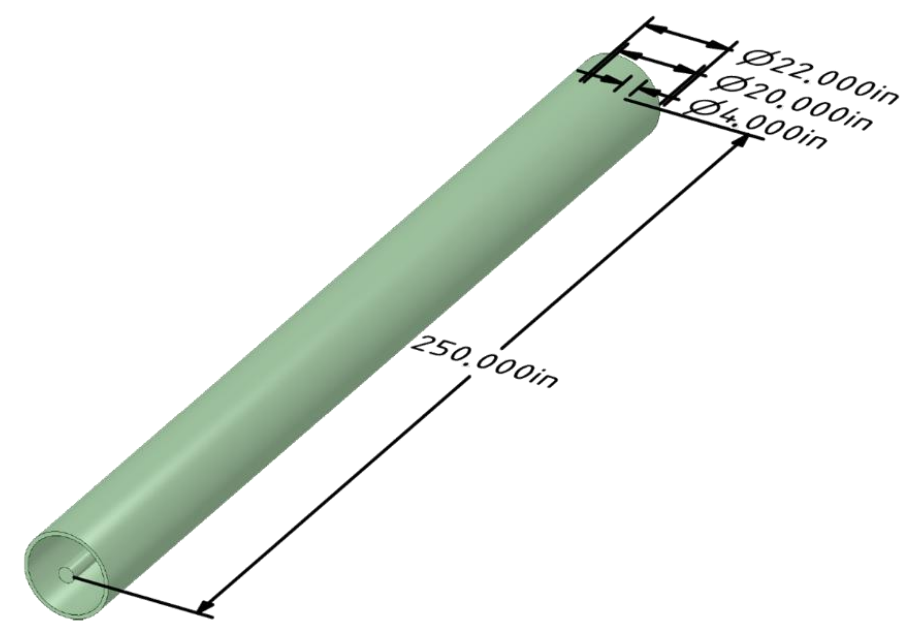

Figure 5. Defined dimensions for $2 \mathrm{~km}$ depth.

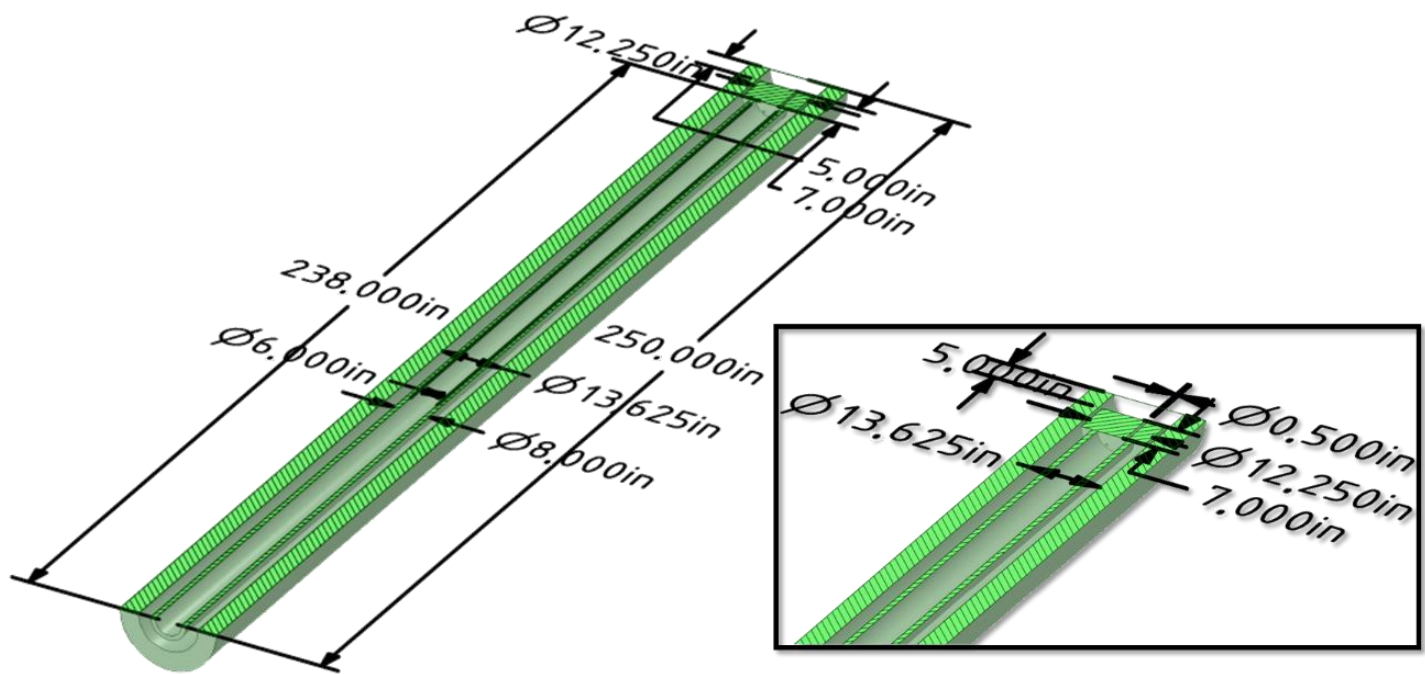

Figure 6. Defined dimensions for $4 \mathrm{~km}$ depth. 
Table 2. Mesh study information.

\begin{tabular}{ccccc}
\hline Mesh Limit $(\mathrm{mm})$ & Elements & RAM $(\mathrm{MB})$ & Time $(\mathrm{s})$ & $\Delta \mathrm{P}(\mathrm{Pa})$ \\
\hline 10 & 556,074 & $6,108.00$ & $1,673.7$ & 278.006 \\
9.5 & 621,375 & $6,671.70$ & $1,864.0$ & 292.970 \\
9.0 & 691,606 & $7,515.05$ & $2,217.8$ & 306.725 \\
8.5 & $1,166,880$ & $6,507.73$ & $5,213.6$ & 284.999 \\
8.0 & $1,333,126$ & $7,328.82$ & $5,928.9$ & 308.354 \\
7.5 & $2,175,568$ & $10,479.53$ & $9,834.8$ & 327.368 \\
7.0 & $2,178,292$ & $10,493.74$ & $9,685.1$ & 341.670 \\
6.5 & $2,724,267$ & $12,764.91$ & $11,838.6$ & 394.246 \\
6.0 & $3,278,664$ & $14,610.18$ & $14,594.6$ & 374.318 \\
\hline
\end{tabular}

Table 3. Number of mesh elements.

\begin{tabular}{lrrrr}
\hline Depth & Mesh limit & \multicolumn{1}{l}{ Fluid } & \multicolumn{1}{c}{ Column } & \multicolumn{2}{c}{ Porous or Casing } \\
\hline $2 \mathrm{~km}$ & $0.70 \mathrm{~cm}$ & $2,178,292$ & 1,760 & 8,208 \\
$4 \mathrm{~km}$ & $0.60 \mathrm{~cm}$ & $8,903,586$ & 185,698 & 6,897 \\
\hline
\end{tabular}

function. A mesh study was performed considering the limits of maximum element size, number of elements generated in the fluid domain, amount of RAM required by the machine, and the time required for convergence, as shown in Table 2. For the analysis of the results, the pressure drop between two planes arranged at 0.2 and 6.2 meters from the origin was evaluated in the case study of two kilometers of depth, and the maximum refinement supported by the RAM in the case of four kilometers.

Comparing the results with each other as a reference, the best equilibrium between number of elements and computational effort achieved was between the tests with 7.0 and 7.5 millimeters of maximum element size. As the time and RAM requirement between both cases were similar, the $7.0 \mathrm{~mm}$ mesh was chosen to better represent the pressure drop (closer to the trend for the most refined meshes). Adopted limits and quantities of elements are shown in Table 3.

For the upper depth, a temperature of $60^{\circ} \mathrm{C}$ and a pressure of $200 \mathrm{~atm}$ were assumed. For the lower depth, the temperature and reference pressure adopted were $119{ }^{\circ} \mathrm{C}$ and $410 \mathrm{~atm}$ (Bourgoyne et al., 1986; Cavalcante et al., 2004; Rocha \& Azevedo, 2009). The evaluated flow rate was 1000 gallons per minute (Silva \& Naccache, 2016) which is equivalent to $0.3243 \mathrm{~m} / \mathrm{s}$ (ascending in annular) at $2 \mathrm{~km}$ and $2.6101 \mathrm{~m} / \mathrm{s}$ at $4 \mathrm{~km}$. In this case, the descending inlet velocity (inside drill pipe) is considered, before the fluid flows internally through the pipe and exits the drill to the annular domain. Residual RMS (root mean square) limits of $10^{-10}$ (from which no quantitative variations greater than $0.01 \%$ were perceived) or 400 maximum iterations (in the case of $4 \mathrm{~km}$, where RMS was not reached) were established. In addition, the HighResolution advection scheme was adopted because it presents high precision even in discontinuities and trilinear interpolation schemes (in detriment of linear-linear interpolations) for pressure and velocity. In addition, parallelization was adopted to reduce the physical time of the solution.

\subsection{Mathematical modelling}

Although the mathematical formulation for axial flow of Bingham's plastic fluid in concentric annulus has broad mathematical development (van Olphen, 1950; Slibar \& Paslay, 1957; Bostandzhiyan, 1970; Anshus, 1974), as cited in the review by Bird et al. (1983), many nonNewtonian fluids (particularly sludge and suspensions) are not well represented either by the Bingham model or by power fluid models. Therefore, a combined formulation with three variables (instead of only two) resulting from the Herschel-Bulkley model is necessary (Herschel \& Buckley, 1926). 


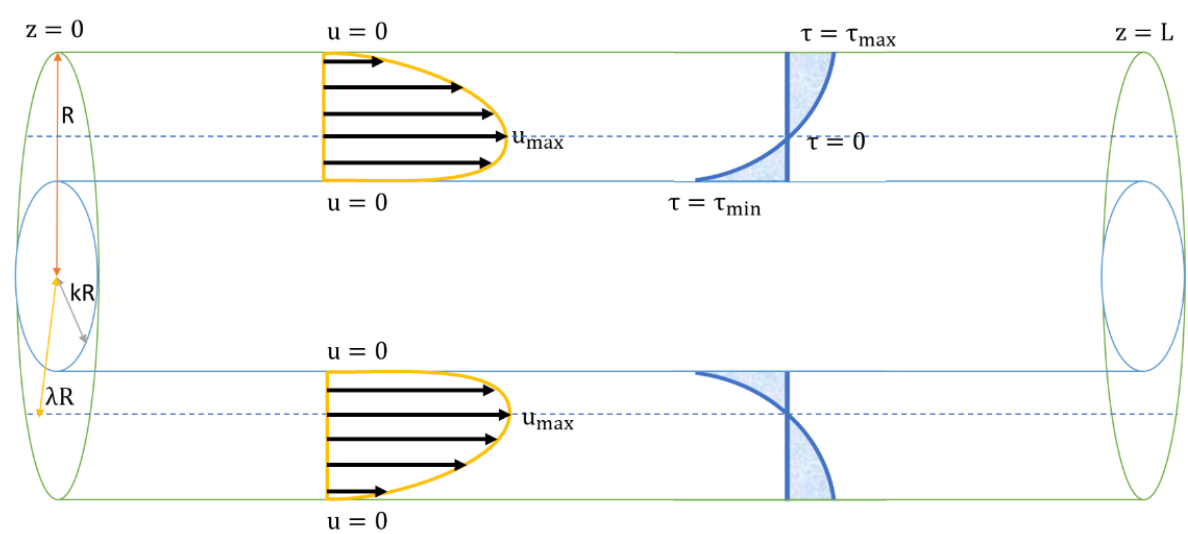

Figure 7. Distribution of speeds and stresses of a fluid flowing through an annular in laminar regime.

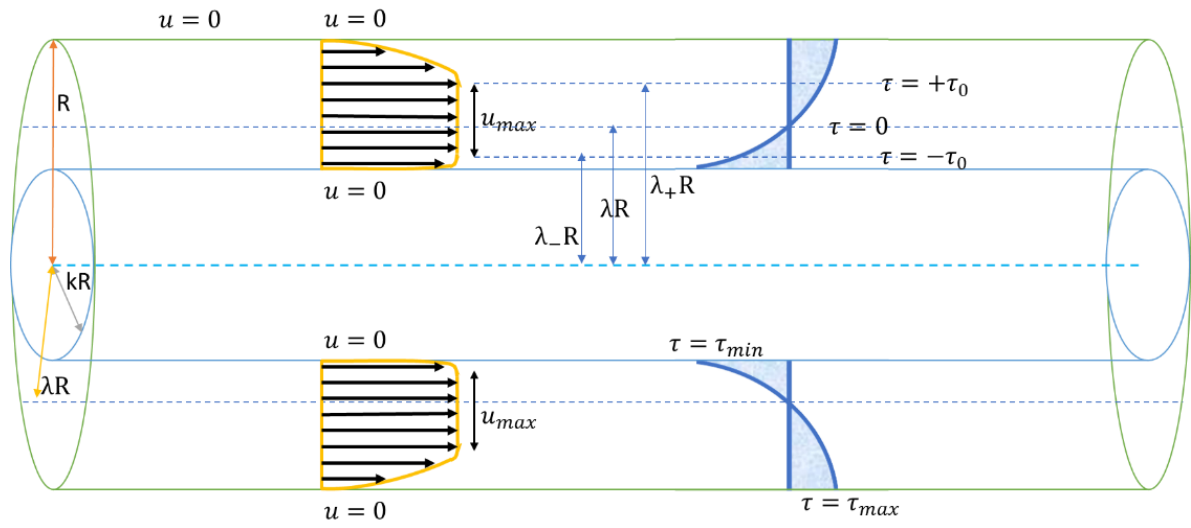

Figure 8. Distribution of speeds and stresses of a fluid flowing through an annular in plug flow.

Based on the mathematical formulation for annular flow from Bird et al. (2002) and Figure 7, the following moment balance can be equated, being $z$ the component in the direction of yielding, $r$ the component in the direction of the cylinder radius and $\theta$ the angular direction, and assuming $u_{r}=u_{\theta}=0, P=P(z) e u_{z}=u_{z}(r)$ :

$\frac{d}{d r}\left(r \cdot \tau_{r z}\right)=\frac{r}{L} \cdot\left(\left(P_{0}-\rho \cdot g \cdot 0\right)-\left(P_{L}+\rho \cdot g \cdot L\right)\right) \equiv$

$\equiv\left(\mathcal{P}_{0}-\mathcal{P}_{L}\right) \cdot \frac{r}{L}$

$\int d\left(r \cdot \tau_{r Z}\right)=\frac{\mathcal{P}_{0}-\mathcal{P}_{L}}{L} \cdot \int r d r \rightarrow$

$\rightarrow r \cdot \tau_{r Z}=\frac{\mathcal{P}_{0}-\mathcal{P}_{L}}{L} \cdot \frac{r^{2}}{2}+C_{1} \rightarrow \tau_{r Z}=\frac{\mathcal{P}_{0}-\mathcal{P}_{L}}{L} \cdot \frac{r}{2}+\frac{C_{1}}{r}$

The moment flow finds nullity when $r=\lambda R$ for both laminar and plug flows, as shown in Figures 7 and 8:

$0=\frac{\mathcal{P}_{0}-\mathcal{P}_{L}}{2 L} \cdot \lambda R+\frac{C_{1}}{\lambda R} \rightarrow \frac{C_{1}}{\lambda R}=-\frac{\mathcal{P}_{0}-\mathcal{P}_{L}}{2 L} \cdot \lambda R \rightarrow$

$\rightarrow C_{1}=-\frac{\mathcal{P}_{0}-\mathcal{P}_{L}}{2 L} \cdot(\lambda R)^{2}$
Replacing the contour condition (5) in the previous Equation (4):

$\tau_{r z}=\frac{\mathcal{P}_{0}-\mathcal{P}_{L}}{2 L} \cdot r-\frac{\mathcal{P}_{0}-\mathcal{P}_{L}}{2 r L}(\lambda R)^{2}=$

$=\frac{\mathcal{P}_{0}-\mathcal{P}_{L}}{2 L}\left(r-\frac{(\lambda R)^{2}}{r}\right)=$

$=\left(\mathcal{P}_{0}-\mathcal{P}_{L}\right) \cdot \frac{R}{2 L}\left(\frac{r}{R}-\lambda^{2} \cdot \frac{R}{r}\right)$

According to Figure 8 , the plug flow region includes $r=\lambda_{-R}$ to $r=\lambda_{+R}$, and these points can be defined, respectively, by $\tau_{r z}=-\tau_{0}$ and $\tau_{r z}=+\tau_{0}$ :

$\lambda_{ \pm}-\frac{\lambda^{2}}{\lambda_{ \pm}}= \pm \frac{2 \tau_{0} \cdot L}{\left(\mathcal{P}_{0}-\mathcal{P}_{L}\right) R} \rightarrow \lambda_{+}-\lambda_{-}=\frac{2 \tau_{0} \cdot L}{\left(\mathcal{P}_{0}-\mathcal{P}_{L}\right) R}$

The basic principles for resolution of numerical problems in fluid dynamics are the moment, energy, and mass balances, which are also the main ones present in both the continuity equation (Equation 11) and Navier-Stokes equation (Equation 12): 
$\frac{\partial \rho}{\partial t}+\vec{\nabla} \cdot(\vec{u} \cdot \rho)=0$

$\frac{\partial(\vec{u} \cdot \rho)}{\partial t}+\vec{\nabla} \cdot(\vec{u} \cdot \rho \times \vec{u})=-\vec{\nabla} \mathcal{P}+\vec{\nabla} \tau+S_{M}$

Although the Reynolds number (nondimensional relationship between inertial and viscous forces, $R e$ ) for a Newtonian fluid may be easily calculated by Equation 13, where $\rho$ refers to the specific mass of the fluid, $D_{h}$ refers to the hydraulic diameter of the duct, $\bar{u}$ is the average velocity of flow, and $\mu$ dynamic viscosity of the fluid. For the flow of a non-Newtonian fluid, the viscosity is not very well defined, so that it is recommended to measure the flow by relating (Equation 14) the number of Reynolds and the Darcy friction factor $\left(f_{\text {Darcy }}\right)$, the latter being defined, as follows, by Equation 15 (Madlener et al., 2009).

$R e=\frac{\rho D_{h} \bar{u}}{\mu}$

$R e=\frac{64}{f_{\text {Darcy }}}$

$f_{\text {Darcy }}=\frac{\left(-\frac{\Delta P}{L}\right) \cdot 2 D_{h}}{\rho \bar{u}^{2}}$

Where $\Delta P$ refers to pressure drop observed between two parallel planes of same hydraulic diameter $D_{h}$ distant by length $L$. By merging
Equations 14 and 15 we obtain:

$R e=\frac{32 \cdot \rho \bar{u}^{2}}{\left(-\frac{\Delta P}{L}\right) \cdot D_{h}}$

\section{RESULTS AND DISCUSSIONS}

Even with the geometric simplification employed in this study (three holes aligned parallel to the internal flow), the current lines caused by the jet resemble those found by Moslemi and Ahmadi (2014). However, one can observe a greater flow development (due to the longer distance between the outflow jet and the bottom of the well) permitting a better visualization of turbulent and shock effects and, subsequent, mud return through the annular region.

As performed with Fluid 2 (YPL), we conducted a test simulation with water flow (therefore a Newtonian fluid) in the flow outlet environment through the drill holes in the 4-kilometer blasting region. Due to the area reduction in the region of the holes, there was a dizzying increase of speeds (which reached about $240 \mathrm{~m} / \mathrm{s}$ ) so that it would not make sense to show a color scale varying from the minimum to the maximum $(0$ and $240 \mathrm{~m} / \mathrm{s}$ respectively). The speed scale was chosen to show the speed differences inside and outside the drill string and, therefore, Figures 9 and 10 indicate the

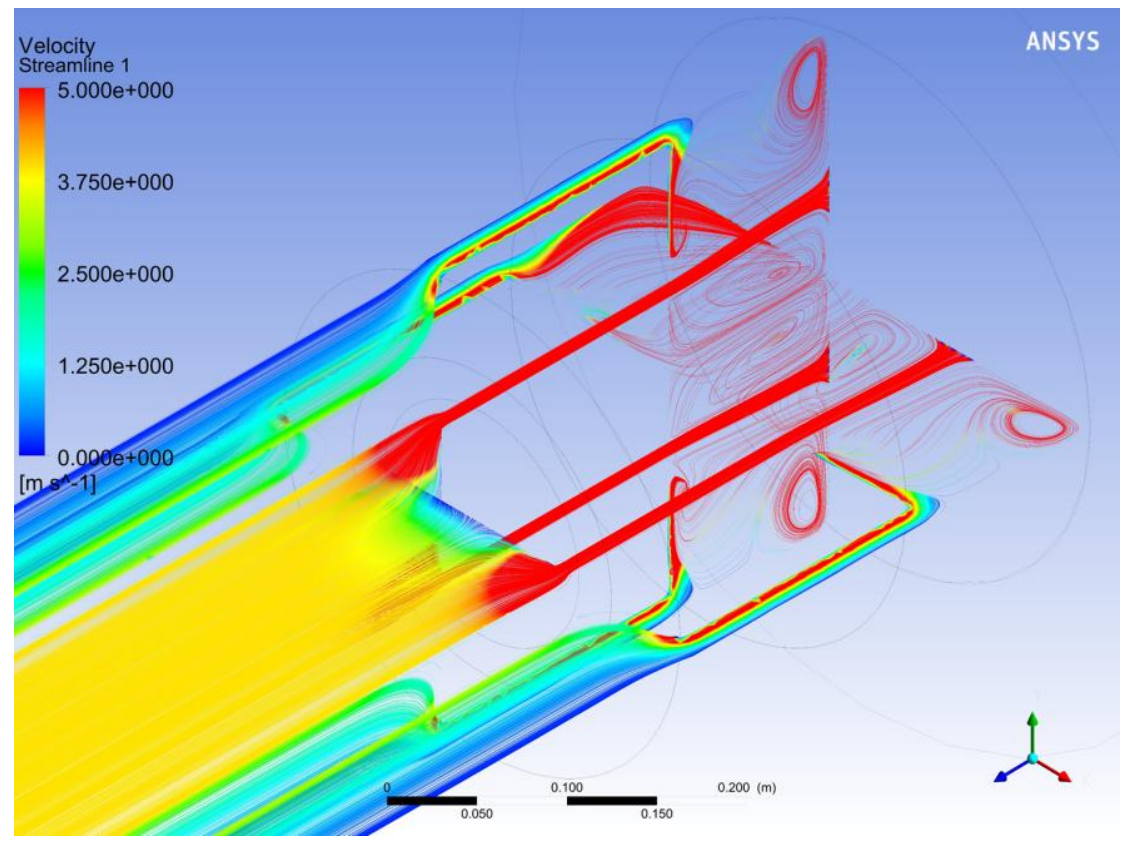

Figure 9. Streamlines of Fluid 2 in $4 \mathrm{~km}$ region. 


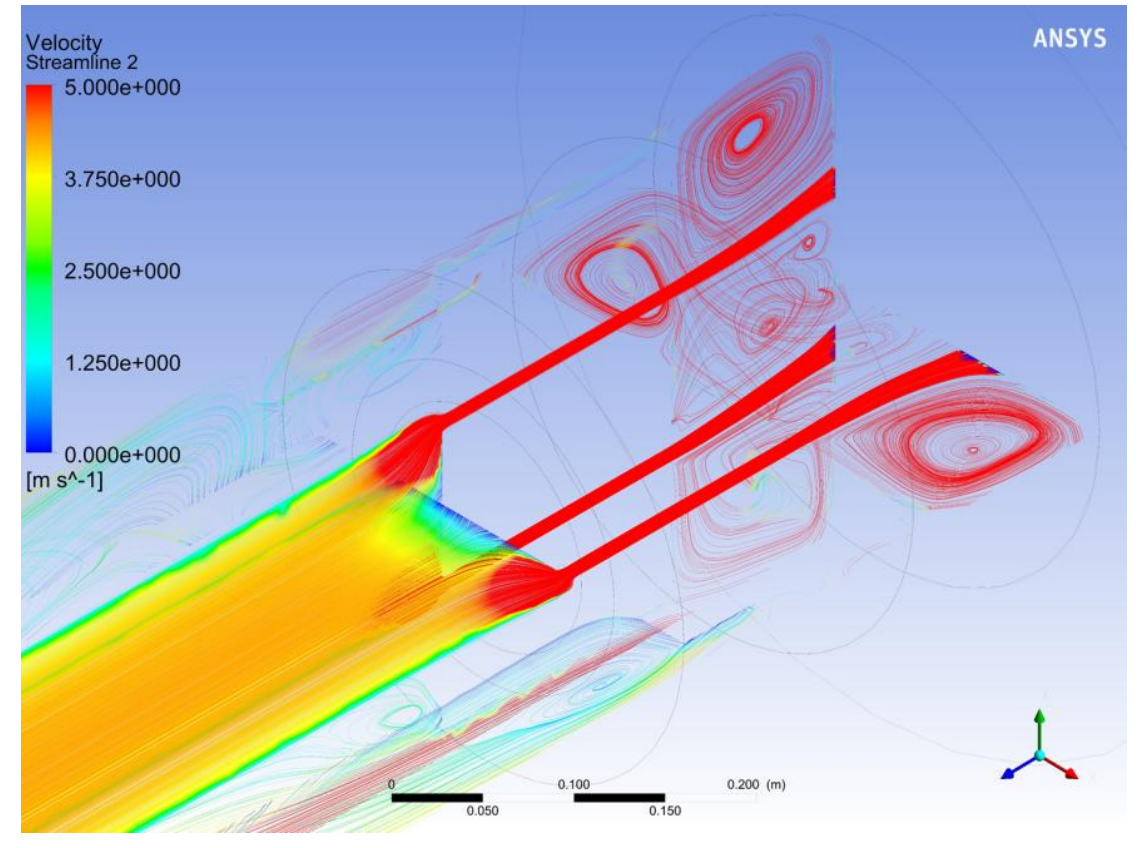

Figure 10. Streamlines of Water in $4 \mathrm{~km}$ region.

current lines for both cases with limited color scales from 0 to $5 \mathrm{~m} / \mathrm{s}$. All regions with higher speeds are displayed with the same red color.

In comparison, the flow with non-Newtonian fluid was much more uniform, with several regions with closer velocities, indicating less dispersion and lower vortices. The velocity limits were quantitatively similar for water and Fluid 2, but with varying distributions. This demonstrates more clearly regions with a greater diversity of flows, since the limited turbulence allows better continuous visualization of currents.

Furthermore, it is important to evaluate the fluid dynamic behavior of the drilling fluid in the fully developed annular flow, since the velocity profile must have plug flow due to the existence of yield stress limit, as shown in Figure 2.

An experiment was conducted to confirm this difference in flows. A simple tubular geometry where two fluids, a Newtonian (water) and a nonNewtonian with yield stress limit flow (the drilling fluid prepared for the work) unifasically in the same geometry in transient regime to allow the observation of the movement of layers. Both fluids should have a similar Reynolds number, thus, ensuring that the only variable to influence the difference between the flows is their rheology, as shown in Table 4.

It was considered a pipe with 8 centimeters $(0.08 \mathrm{~m})$ in diameter and half meter $(0.5 \mathrm{~m})$ length. Also included in post-processing were two planes discarding $10 \%(5 \mathrm{~cm}$ or $0.05 \mathrm{~m}$ ) of entry and exit (to avoid effects of mesh ends). The average velocity was calculated as the average between the average velocities calculated in both planes evaluated, and the pressure drop is equal to the pressure difference measured in these two planes.

Table 4. Pipeline dimensions and characteristics of the fluids evaluated.

\begin{tabular}{lcc}
\hline Variable measured & Mud & Water \\
\hline Pipe length $(\mathrm{m})$ & \multicolumn{2}{c}{0.5} \\
Hydraulic diameter $(\mathrm{m})$ & \multicolumn{2}{c}{0.08} \\
Density $\left(\mathrm{kg} / \mathrm{m}^{3}\right)$ & 1054.5 & 997 \\
Average velocity $(\mathrm{m} / \mathrm{s})$ & 1.2 & 0.013 \\
Pressure gradient $(\mathrm{Pa})$ & 201.983 & - \\
Dynamic viscosity (Pas) & - & $8.899 \mathrm{e}-4$ \\
\hline
\end{tabular}




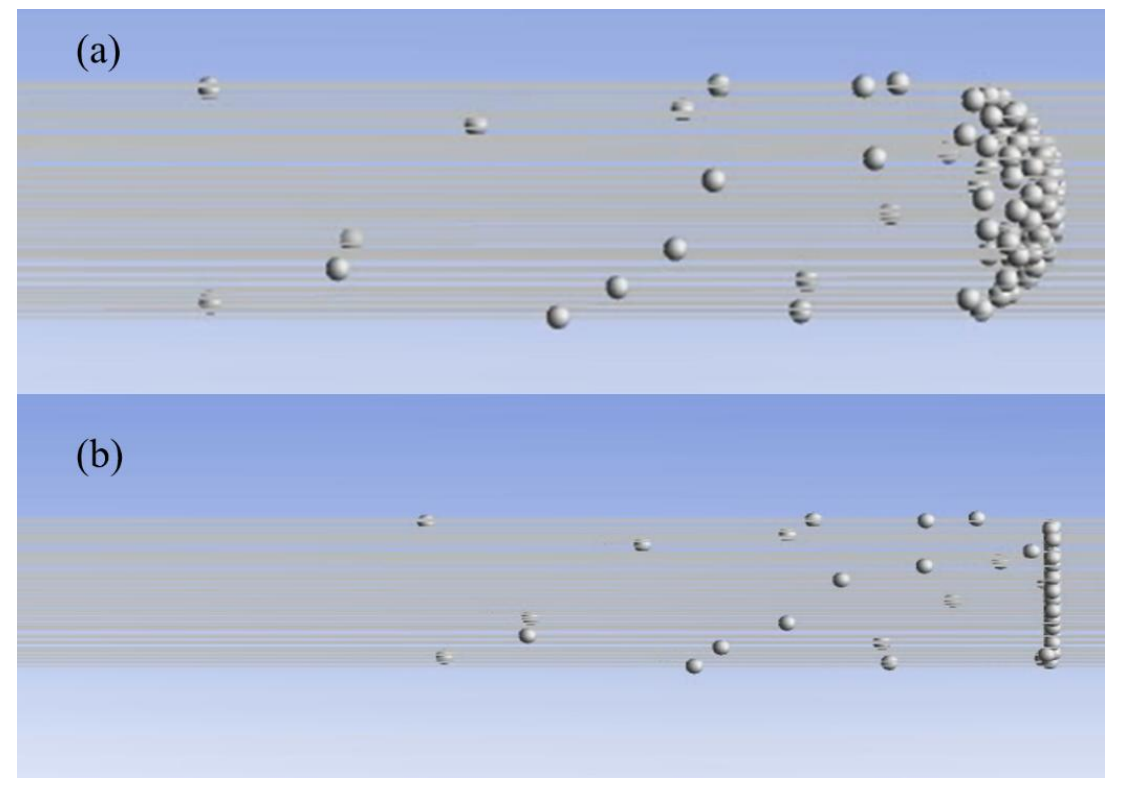

Figure 11. Velocity profiles in a pipe of water (a) and non-Newtonian fluid (b).
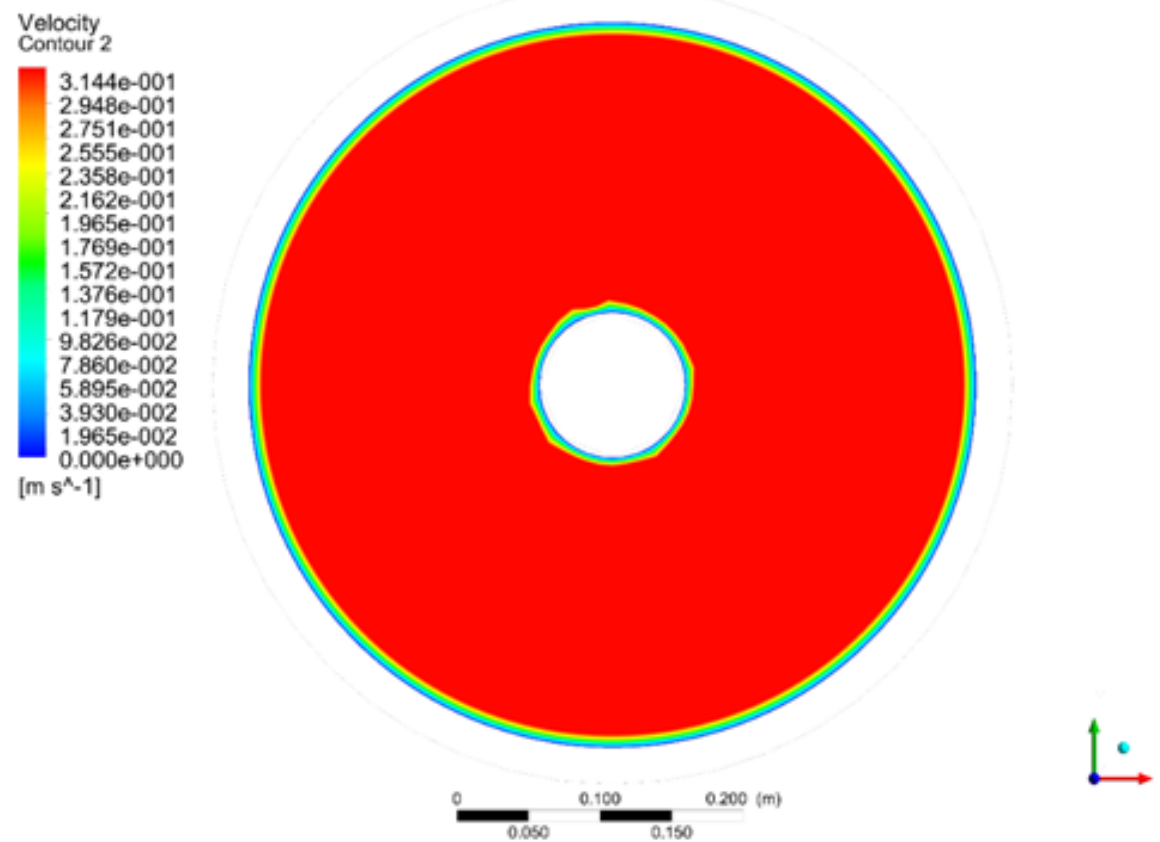

Figure 12. Velocities distribution of Fluid 2 in the $Z$ axis of the 2,000 m annular.

Figure 11a demonstrates the well-known laminar flow of the Newtonian fluid while Figure $11 \mathrm{~b}$ indicates a typical plug behavior of fluids with yield stress limit, such a fluid made with xanthan gum and bentonite clay. It is, thus, possible to understand the considerable difference between the flows already well developed mathematically (Bird et al., 2002). According to Figures 7 and 8, this behavior should be extended to the flow within an annular.
With the implementation of the final geometric model, an effect equivalent to Figure 8 should be found demonstrating the so-called "plug flow region" (between $\lambda_{-} R \leq r \leq \lambda_{+} R$ ) centralized and the "plastic flow regions" (between $k R \leq r \leq \lambda_{-} R$ and $\left.\lambda_{+} \leq r \leq R\right)$. The region where the shear stress is null $(\tau=0)$ is called yield surface and in a situation of coaxial pipes is displaced to the central axis. Geometrically, it is not a very noticeable effect, as illustrated in Figure 12, but it is visible (in 

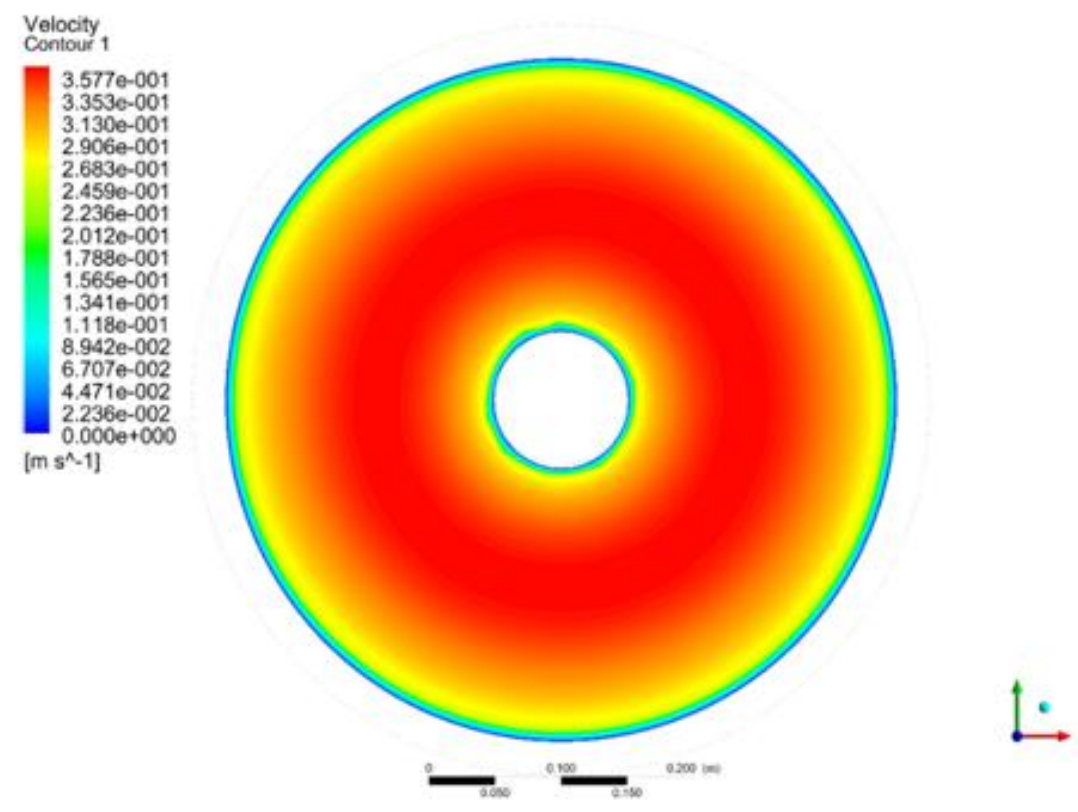

Figure 13. Velocities distribution of Water in the $Z$ axis of the $2,000 \mathrm{~m}$ annular.

Figure 13) in the velocity distribution corresponding to the Newtonian fluid flow.

While Figure 12 refers to the non-Newtonian behavior in an annular (as shown in Figure 8), Figure 13 indicates the Newtonian behavior of water allowing one to notice the displacement of the maximum velocity tending to internal radius, as shown in Figure 7.

In annular environments, turbulence is harmful and can impact the structural stability of formations. The ability of a drilling fluid to ensure stability during drilling is one of the most relevant criteria for its selection. At the bottom of the well, it is important to have greater movement of particles, i.e. turbulence, to avoid fluid preferential paths that could keep the cuttings interfering in drilling. However, excessive vorticity also does not guarantee good well cleaning and should be controlled for the sake of drilling (Lim \& Chukwu, 1996).

\section{CONCLUSIONS}

As mentioned previously, rheological conditions are very dependent on thermal and compressive variations, and these rheological relations have a significant influence on fluid dynamics. In addition, there is still a long way to go to ensure safe extrapolations of these property relationships so that numerical studies of these behaviors can help, but not replace empirical viscosimetric tests.

The finite volume model was successfully developed with initial and boundary conditions based on empirical tests. This model allowed us to evaluate the fluid dynamic flow of a drilling mud under annular conditions and in jetting region, representing the descriptions found in the literature. Rheological conditions of the fluid were measured in laboratory using a viscosimeter and shall assist in extrapolation of fluid dynamic parameters under extreme temperature and pressure conditions.

A comparison of flows between a Newtonian fluid (water) and two non-Newtonian yield fluids (represented as Bingham plastic and HerschelBulkley) was performed. A good understanding of fluid dynamics in the drill region is important to measure the well cleanliness. This ensures good drill activity, optimizing rate of penetration (ROP).

Thermal and compression conditions in ultradeep regions are a latent challenge of both equipment and rheological behavior. Significant academic efforts have been made to model the 
hydraulic behavior in these conditions. Numerical simulations can favor an accelerated advance in the comprehension of these conditions as long as they are aligned with reliable experimental data.

\section{NOMENCLATURE}

Greek Letters

$\gamma$ - Shear rate $\left[s^{-1}\right]$

$\theta$ - Angular component $[\mathrm{rad}]$

$\mu$ - Dynamic viscosity $[\mathrm{Pa} \cdot \mathrm{s}]$

$\mu_{p}$ - Plastic viscosity $[\mathrm{Pa} \cdot \mathrm{s}]$

$\rho$ - Density $\left[\mathrm{kg} / \mathrm{m}^{3}\right]$

$\tau$-Shear stress $[\mathrm{Pa}]$

$\tau_{0}-$ Yield stress limit $[\mathrm{Pa}]$

Symbols

$D_{n}$ - Deflection obtained at $n$ rotation of viscometer [lbf $\left./ 100 f t^{2}\right]$

$D_{h}$ - Hydraulic diameter $[\mathrm{m}]$

$f_{\text {Darcy }}$ - Darcy friction factor [-]

$g-$ Gravitational acceleration $\left[\mathrm{m} / \mathrm{s}^{2}\right]$

$\mathrm{K}$ - Consistency index $\left[\mathrm{Pa} \cdot \mathrm{s}^{n}\right]$

$L$ - Length $[m]$

$n$ - Behavior index $[-]$

$P$ - Pressure $[\mathrm{Pa}]$

$\mathcal{P}$ - Sum of pressure and gravitational terms $[\mathrm{Pa}]$

$r$-Radial component $[\mathrm{m}]$

$R e-$ Reynolds number [-]

$S_{M}$-Sum of other moment forces $[\mathrm{Pa}]$

$t-$ Time $[s]$

$u$-Velocity of flow $[\mathrm{m} / \mathrm{s}]$

\section{REFERENCES}

Anshus, B. E. Bingham plastic flow in annuli. Industrial \& Engineering Chemistry Fundamentals, v. 13(2), p. 162-164, 1974. https://doi.org/10.1021/i160050a016

API - American Petroleum Institute. API Recommended Practice 13A. Specification for Drilling-Fluid Materials, 2006.
API - American Petroleum Institute. API Recommended Practice 13D. Rheology and Hydraulics of Oil-well Fluids, 2009.

Bird, R. B.; Dai, G. C.; Yarusso, B. J. The Rheology and flow of viscoplastic materials. Reviews in Chemical Engineering, v. 1(1), p. 1-70, 1983. https://doi.org/10.1515/revce-1983-0102

Bird, R. B.; Stewart, W. E.; Lightfoot, E. N. Transport Phenomena, $2^{\text {nd }}$ ed. USA: John Wiley \& Sons, 2002.

Bostandzhiyan, S. A. Axial laminar flow of a viscoplastic fluid in an annular tube. Journal of Engineering Physics, v. 18(6), p. 761-767, 1970. https://doi.org/10.1007/BF00827853

Bourgoyne, A. T.; Millheim, K. K.; Chenevert, M. E.; Young, F. S. Applied Drilling Engineering. Texas: SPE Textbook Series, Society of Petroleum Engineers, v. 2, 1986.

Caenn, R.; Darley, H. C. H.; Gray, G. R. Composition and Properties of Drilling and Completion Fluids. $6^{\text {th }}$ Ed. Massachusetts: Elsevier, 2011.

Cameron, C. Drilling fluids and management for extended reach drilling. SPE/IADC Middle East Drilling Technology Conference, 22-24 October, Bahrain, 2001. https://doi.org/10.2118/72290-MS

Cavalcante, A. G.; Argollo, R. M.; Carvalho, H. S. Correção de dados de temperatura de fundo de poço (TFP). Revista Brasileira de Geofísica, v. 22(3), p. 233-243, 2004. (in Portuguese) https://doi.org/10.1590/S0102-261X2004000300003

Chung, T. J. Computational Fluid Dynamics. $2^{\text {nd }}$ Ed. Cambridge: Cambridge University Press, 2010.

Hanks, R. W. The axial laminar flow of yieldpseudoplastic fluids in a concentric annulus. Industrial \& Engineering Chemistry Process Design and Development, v. 18(3), p. 488-493, 1979. https://doi.org/10.1021/i260071a024

Herschel, W. H.; Bulkley, R. Konsistenzmessungen von Gummi-Benzollösungen. Colloid and Polymer Science, v. 39(4), p. 291-300, 1926. (in German) https://doi.org/10.1007/BF01432034 
Kendall, H. A.; Goins Jr., W. C. Design and operation of jet-bit programs for maximum hydraulic horsepower, impact force or jet velocity. Petroleum Transactions, AIME, v. 219, p. 238-250, 1960.

Lee, J.; Shadravan, A.; Young, S. Rheological properties of invert emulsion drilling fluid under extreme HPHT conditions. IADC/SPE-151413, IADC/SPE Drilling Conference and Exhibition, San Diego, California, USA, 6-8 March, 2012. https://doi.org/10.2118/151413-MS

Lim, K. M.; Chukwu, G. A. Bit hydraulics analysis for eficient hole cleaning. SPE-35667-MS. SPE Western Regional Meeting, Anchorage, Alaska, 2224 May, 1996. https://doi.org/10.2118/35667-MS

Machado, J. C. V. Reologia e escoamento de fluidos: Ênfase na indústria do petróleo. Rio de Janeiro: Interciência, 2002. (in Portuguese)

Madlener, K.; Frey, B.; Ciezki, H. K. Generalized Reynolds number for non-newtonian fluids. Progress in propulsion physics, v. 1, p. 237-250, 2009. https://doi.org/10.1051/eucass/200901237

Melo, K. C. Avaliação e modelagem reológica de fluidos de perfuração base água. 100f. Dissertação de Mestrado. Programa de Pós-Graduação em Engenharia Química, Universidade Federal do Rio Grande do Norte, Natal, RN, 2008. (in Portuguese)

Moslemi, A.; Ahmadi, G. Study of the hydraulic performance of drill bits using a computational particle-tracking method. SPE-169812-PA. SPE Drilling \& Completion, v. 29(1), p. 28-35, 2014. https://doi.org/10.2118/169812-PA
Rassenfoss, S. Oil tests at extreme conditions yield new data for reservoir modeling. Journal of Petroleum Technology, v. 66(11), p. 74-75, 2014. https://doi.org/10.2118/1114-0074-JPT

Rocha, L. A. S.; Azevedo, C. T. Projeto de poços de petróleo: Geopressões e assentamento de colunas de revestimentos. $2^{\text {nd }}$ Ed. Rio de Janeiro: Interciência, 2009. (in Portuguese)

Shadravan, A.; Amani, M. HPHT 101: What every engineer or geoscientist should know about High Pressure High Temperature wells. SPE-163376-MS. SPE Kuwait International Petroleum Conference and Exhibition, Society of Petroleum Engineers, Kuwait City, Kuwait, 10-12 December, 2012. https://doi.org/10.2118/163376-MS

Silva, T. P.; Naccache, M. Enhanced fluid rheology characterization for managed pressure drilling applications. SPE-180070-MS. SPE/IADC Managed Pressure Drilling and Underbalanced Operations Conference and Exhibition, Galveston, Texas, USA, 12-13 April, 2016.

Slibar, A.; Paslay, P. R. Die axiale Strömung von Bingham Plastiken in konzentrischen Rohren. Journal of Applied Mathematics and Mechanics, v. 37(11-12), p. 441-449, 1957. (in German) https://doi.org/10.1002/zamm.19570371105

van Olphen, H. Pumpability, rheological properties, and viscometry of drilling fluids. Journal of the Institute of Petroleum, v. 36, p. 223-234, 1950. 